\title{
Front Matter: Volume 9292
}

, "Front Matter: Volume 9292," Proc. SPIE 9292, 20th International Symposium on Atmospheric and Ocean Optics: Atmospheric Physics, 929201 (3 December 2014); doi: 10.1117/12.2177947

SPIE Event: 20th International Symposium on Atmospheric and Ocean Optics: Atmospheric Physics, 2014, Novosibirsk, Russian Federation 


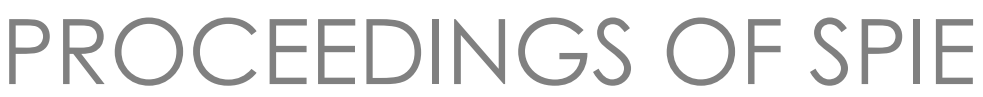

\title{
20th International Symposium on Atmospheric and Ocean Optics: Atmospheric Physics
}

\author{
Gennadii G. Matvienko \\ Oleg A. Romanovskii \\ Editors
}

23-27 June 2014

Novosibirsk, Russian Federation

Organized by

V.E. Zuev Institute of Atmospheric Optics (Russian Federation)

V.V. Voevodsky Institute of Chemical Kinetics and Combustion (Russian Federation)

Institute of Solar-Terrestrial Physics (Russian Federation)

Sponsored by

Russian Foundation for Basic Research (Russian Federation)

Siberian Branch of Russian Academy of Sciences (Russian Federation)

Published by

SPIE

Volume 9292

Part One of Two Parts

Proceedings of SPIE 0277-786X, V. 9292

SPIE is an international society advancing an interdisciplinary approach to the science and application of light.

20th International Symposium on Atmospheric and Ocean Optics: Atmospheric Physics, edited

by Gennadii G. Matvienko, Oleg A. Romanovskii, Proc. of SPIE Vol. 9292, 929201 - (C) 2014

SPIE $\cdot$ CCC code: $0277-786 X / 14 / \$ 18 \cdot$ doi: $10.1117 / 12.2177947$ 
The papers included in this volume were part of the technical conference cited on the cover and title page. Papers were selected and subject to review by the editors and conference program committee. Some conference presentations may not be available for publication. The papers published in these proceedings reflect the work and thoughts of the authors and are published herein as submitted. The publisher is not responsible for the validity of the information or for any outcomes resulting from reliance thereon.

Please use the following format to cite material from this book:

Author(s), "Title of Paper," in 20th International Symposium on Atmospheric and Ocean Optics: Atmospheric Physics, edited by Gennadii G. Matvienko, Oleg A. Romanovskii, Proceedings of SPIE Vol. 9292 (SPIE, Bellingham, WA, 2014) Article CID Number.

ISSN: 0277-786X

ISBN: 9781628413762

Published by

SPIE

P.O. Box 10, Bellingham, Washington 98227-0010 USA

Telephone +1 3606763290 (Pacific Time) · Fax +1 3606471445

SPIE.org

Copyright (c) 2014, Society of Photo-Optical Instrumentation Engineers.

Copying of material in this book for internal or personal use, or for the internal or personal use of specific clients, beyond the fair use provisions granted by the U.S. Copyright Law is authorized by SPIE subject to payment of copying fees. The Transactional Reporting Service base fee for this volume is $\$ 18.00$ per article (or portion thereof), which should be paid directly to the Copyright Clearance Center (CCC), 222 Rosewood Drive, Danvers, MA 01923. Payment may also be made electronically through CCC Online at copyright.com. Other copying for republication, resale, advertising or promotion, or any form of systematic or multiple reproduction of any material in this book is prohibited except with permission in writing from the publisher. The CCC fee code is 0277-786X/14/\$18.00.

Printed in the United States of America.

Publication of record for individual papers is online in the SPIE Digital Library.

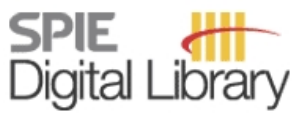

SPIEDigitalLibrary.org

Paper Numbering: Proceedings of SPIE follow an e-First publication model, with papers published first online and then in print and on CD-ROM. Papers are published as they are submitted and meet publication criteria. A unique, consistent, permanent citation identifier (CID) number is assigned to each article at the time of the first publication. Utilization of CIDs allows articles to be fully citable as soon as they are published online, and connects the same identifier to all online, print, and electronic versions of the publication. SPIE uses a six-digit CID article numbering system in which:

- The first four digits correspond to the SPIE volume number.

- The last two digits indicate publication order within the volume using a Base 36 numbering

system employing both numerals and letters. These two-number sets start with 00, 01, 02, 03, 04, 05, 06, 07, 08, 09, 0A, 0B ... 0Z, followed by 10-1Z, 20-2Z, etc.

The CID Number appears on each page of the manuscript. The complete citation is used on the first page, and an abbreviated version on subsequent pages. Numbers in the index correspond to the last two digits of the six-digit CID Number. 


\title{
Contents
}

\author{
XV Authors \\ xxi Conference Committees \\ xxv Introduction
}

\section{Part One}

\section{MOLECULAR SPECTROSCOPY AND ATMOSPHERIC RADIATIVE PROCESSES}

929202 High resolution diode laser spectroscopy of $\mathrm{H}_{2} \mathrm{O}$ spectra broadened by nitrogen and noble gases [9292-146]

929203 The self-broadened, isolated $\mathrm{CO}_{2}$ spectral line shape investigation [9292-147]

929204 Theoretical studies of pressure broadened halfwidths of symmetric tops: $\mathrm{CH}_{3} \mathrm{CN}-\mathrm{CH}_{3} \mathrm{CN}$ and $\mathrm{CH}_{3} \mathrm{Cl}-\mathrm{CO}_{2}$ [9292-154]

929205 Estimation of uncertainties in the longwave radiative fluxes simulation due to spectroscopic errors [9292-208]

929206 Modelling vibrational-rotational interactions in intensities of $\mathrm{v}_{2}$ band $\mathrm{H}_{2} \mathrm{O}$ by Pade approximants [9292-109]

929207 Zeeman Effect treatment in the infrared spectrum of the nitric oxide molecule [9292-148]

929208 Measurement of $\mathrm{SO}_{2}$ absorption spectra in the UV spectral region [9292-152]

929209 Representation of absorption cross sections in information system W@DIS [9292-159]

9292 OA Systematization of published spectral data on sulfur dioxide molecule and its isotopologues [9292-217]

9292 OB Systematization of published spectral data on deuterated isotopologues of hydrogen sulfide molecule [9292-248]

9292 0C An ontological description of states and transitions in quantitative spectroscopy [9292-197]

9292 OD The influence absorb stratification on absorptivity of atmosphere [9292-174]

$92920 \mathrm{E}$ the influence of underlying surface on reflectivity of layer atmosphere [9292-165]

9292 OF Description of metastable states in the asymptotic line shape theory [9292-94]

$92920 \mathrm{OG}$ A description of the $\mathrm{H}_{2} \mathrm{O}$ absorption in the 3-5 $\mu \mathrm{m}$ spectral region in violation of the longwave approximation in line wings [9292-100] 
$9292 \mathrm{OH} \quad$ Continuum absorption in the $4.3 \mu \mathrm{m} \mathrm{CO} 2$ band [9292-96]

$9292 \mathrm{Ol} \quad$ Spectral linelist of HD16 $\mathrm{O}$ molecule based on VTT calculations for atmospheric application [9292-144]

$92920 \mathrm{~J}$ Fourier-transform absorption spectrum of $\mathrm{H}_{2} \mathrm{O}$ in the region of $15500-16000 \mathrm{~cm}^{-1}$ [9292-132]

$9292 \mathrm{OK} \quad \mathrm{H}_{2}{ }^{16} \mathrm{O}$ absorption spectrum between 22250 and $22800 \mathrm{~cm}^{-1}$ : Fourier transform spectroscopy with bright light source [9292-163]

$9292 \mathrm{OL} \quad$ On effects of isolated cloud on irradiance at the Earth's surface in the range of 0.4-0.7 $\mu \mathrm{m}$ : results of numerical simulation [9292-69]

9292 OM Line broadening estimate from averaged energy differences of coupled states [9292-156]

$9292 \mathrm{ON}$ The $\mathrm{D}_{2} \mathrm{O}$ absorption spectra in the treatment surfaces $\mathrm{SiO}_{2}$ airgel [9292-73]

$929200 \quad D_{2} \mathrm{O}$ self-broadening study in $\mathbf{2 . 5} \boldsymbol{\mu}$ [9292-74]

9292 OP On the vibrational dependence of the quantum intermolecular interaction potential [9292-173]

\section{OPTICAL RADIATION PROPAGATION IN THE ATMOSPHERE AND OCEAN}

$92920 Q \quad$ Vortex laser beam in a randomly inhomogeneous medium (Invited Paper) [9292-251]

9292 OR Eddy mixing in planetary boundary layer and free atmosphere (Invited Paper) [9292-78]

9292 OS The effect of multiple scattering on polarization and angular distributions for radiation reflected by clouds: results of Monte Carlo simulation (Invited Paper) [9292-27]

9292 OT Optical turbulence and different parameters of airflow [9292-44]

$92920 \mathrm{U}$ Simulation of coherent structures (topological solitons) indoors by numerical solving of hydrodynamics equations [9292-212]

$92920 \mathrm{~V}$ Intermittency of the astronomical images jitter in the high-mountain observations [9292-47]

9292 OW Remaining distortions, conditioned dimension of guide source [9292-239]

9292 OX Flight study of on-board enhanced vision system for all-weather aircraft landing [9292-220]

9292 OY Numerical radiative transfer modeling in turbid medium slab [9292-56]

$9292 \mathrm{OZ}$ Photophoretic motion of fractal-like soot aggregates: experiment and theory comparison [9292-70]

929210 Atmospheric bistatic optoelectronic communication systems: field experiments [9292-67]

929211 Optical-physical methods of remote diagnostics of high-temperature gas media [9292-114] 
929212 Direction and movement angular velocity determining of cloudiness with panoramic images of the sky [9292-72]

929213 Analysis of efficiency of the correlation algorithm calculating the speed of the cross wind transfer of the turbulence by data of Shack-Hartmann sensor [9292-98]

929214 Experimental research of optical properties of flame using methods IR diagnostics [9292-58]

929215 Choice for research spectral response of combustion processes using the method of IR diagnostics [9292-59]

$929216 \quad$ Nonequilibrium statistics of the laser beam intensity profile at the output of a model channel with strong turbulence [9292-218]

929217 Spectral composition of inhomogeneities of intensity of laser beam translucent the supersonic jet near the nozzle [9292-68]

929218 Effect of the initial field's phase dislocation on the intensity enhancement factor of the laser beam backscattered off a diffuse target [9292-133]

929219 Comparison of the ray-tracing and beam-tracing methods in the problem of light scattering by ice crystals of cirrus clouds [9292-207]

9292 1A Extremal localization of optical field near surface of spherical dielectric microparticles [9292-150]

9292 1B Filamentation of terawatts lasers pulses on 100m atmospheric path [9292-224]

9292 1C Spatial characteristics of the gigawatt laser pulses filamentation area at their different focusing on atmospheric path [9292-221]

9292 1D Multiple filamentation of collimated beams Ti:Sapphire-laser in water [9292-227]

$92921 \mathrm{~A} \quad$ A numerical simulation method for laser radiation propagating through large-scale atmospheric inhomogeneities [9292-122]

$92921 \mathrm{~F} \quad$ Determination of atmospheric turbulent inhomogeneity wind drift from sequence of incoherent images [9292-232]

$92921 \mathrm{G} \quad$ Ring dislocation of a coherence of vortex Bessel beams in turbulent atmosphere [9292-108]

$92921 \mathrm{H} \quad$ Passive differential method of sounding of maintenance of sodium in atmosphere [9292-234]

$929211 \quad$ Formation of "photonic jet" upon irradiation of spherical microparticles by a focused laser beam [9292-149]

$92921 \mathrm{~J}$ Influence of regular and random distortions on quality of multichannel laser radiation [9292-126]

$92921 \mathrm{~K} \quad$ Coherence of vortex beams in discrete scattering media [9292-76] 
$92921 \mathrm{~L} \quad$ Spatial coherence and mean intensity of backscattered short-pulse optical radiation [9292-52]

$92921 \mathrm{M}$ Fluctuations of vortex beam parameters in a turbulent atmosphere [9292-130]

$92921 \mathrm{~N}$ Diffraction of optical beam at a shock wave arising near supersonic aircraft [9292-57]

929210 Determination of clouds motion characteristics in the atmosphere with lidar and digital cameras [9292-66]

$92921 \mathrm{P} \quad$ Numerical simulation of correlation method calculating the transverse component of the wind speed on basis of the measurements on the Shack-Hartmann sensor [9292-97]

$92921 Q \quad$ Laguerre-Gaussian beam broadening in the turbulent atmosphere [9292-65]

9292 IR Mean intensity of vortex Bessel beams in turbulent atmosphere [9292-25]

9292 is Aerosol lidar to study the atmospheric backscatter amplification [9292-142]

9292 1T Propagation of coherent scalar vortex beams $L_{0 L}$ through a randomly inhomogeneous medium [9292-238]

$92921 \mathrm{U}$ Determination of the optical turbulence intensity from data measured by a coherent Doppler lidar [9292-23]

$92921 \mathrm{~V}$ Calculation of the profile of turbulent inhomogeneities of the air refraction index [9292-104]

$92921 \mathrm{~W}$ Statistical properties of the beam horizontal shifts at oblique reflection from a layer with random dielectric permittivity inhomogeneities [9292-49]

$92921 \mathrm{X}$ Propagation focus repetitively pulsed laser radiation in gas-aerosol atmosphere [9292-247]

$92921 Y \quad$ Mathematical modeling of space-time profiles of heterogeneous media temperature [9292-103]

929212 Scattering properties of spherically aggregated metal nanoparticles in active matrix [9292-89]

929220 Random displacement of the Bessel-Gaussian beam in turbulent atmosphere [9292-32]

929221 Comparative measurements of the level of turbulence atmosphere by optical and acoustic devices [9292-240]

929222 Experimental study of the depth of the combustion front of peat by IR methods [9292-304]

929223 Experimental study of wood ignition caused by heat from the combustion front of the peat layer [9292-305]

929224 Mathematical modeling of ignition of woodlands resulted from accident on the pipeline [9292-302]

929225 Mathematical modeling of surface forest fires transition into crown forest fires [9292-301] 
929226 Study of flame characteristics during liquid hydrocarbons combustion with steam gasification [9292-303]

\section{OPTICAL INVESTIGATION OF ATMOSPHERE AND OCEAN}

929227 Backscatter-depolarisation lidars on high-altitude research aircraft (Invited Paper) [9292-229]

929228 Lidar studies of microphysical properties of cirrus clouds (Invited Paper) [9292-186]

929229 Improvement of the sensitivity of a stationary Raman gas analyzer [9292-171]

9292 2A Calibration and preliminary tests of the optoelectronic dual channel precipitation gauge [9292-5]

9292 2B Analysis of experiments on high-level cloud sensing with a satellite radiometer and a ground-based polarization lidar [9292-242]

$92922 \mathrm{C}$ Calculation of polarization characteristics of lidar return from clouds in double scattering approach [9292-245]

9292 2D Application of an electro-optical shutter for strobing of lidar signals [9292-42]

$92922 \mathrm{E}$ The comparison of the results of numerical modeling and physical model experiment on laser polarization sensing of droplet clouds [9292-139]

$9292 \mathrm{2F}$ Software system for numerical simulation of minor gas constituents lidar sensing by the differential absorption method [9292-185]

$92922 \mathrm{G}$ Remote detector of explosive traces [9292-19]

$92922 \mathrm{H} \quad$ Comparison of the geometrical and physical optics approximations for solving the problem of light scattering by quasi-horizontally oriented ice plates [9292-54]

929221 Simulation of the potential capabilities of measuring the density of the middle atmosphere from onboard ISS [9292-213]

9292 2J Experimental study of the interaction between terahertz radiation from the Novosibirsk freeelectron laser and water aerosol [9292-99]

$92922 \mathrm{~K} \quad$ Use of terahertz spectroscopy for reconstruction of the aerosol particle size distribution spectrum by the spectral transparency method [9292-101]

9292 2L Analysis microstructure of the upper-level clouds by polarization characteristics of lidar returns [9292-82]

9292 2M Investigation of phase matrices of cirrus containing ensembles of oriented ice particles [9292-210]

9292 2N Software system for simulation IPDA lidar sensing from space platform [9292-105] 
929220 Outer scales of temperature turbulence and dynamic turbulence from the data of acoustic sounding of the atmosphere [9292-199]

9292 2P Optical system synthesis for lidar transmitting channel [9292-155]

\section{Part Two}

$92922 \mathrm{Q}$ Identification of the functional groups on the surface of nanoparticles formed in photonucleation of aldehydes generated during forest fire events [9292-214]

9292 2R Aerosol index variations caused by severe forest fires in Siberia [9292-45]

9292 2S Diurnal variability of aerosol extinction of optical radiation in the surface atmosphere West Siberia [9292-117]

9292 2T Extinction and scattering of optical radiation under smoke and clean conditions [9292-123]

$92922 \mathrm{U} \quad$ Retrieval of the aerosol optical and microphysical parameters from the data of measurements by means of Aurora 4000 nephelometer [9292-252]

$92922 \mathrm{~V}$ The measuring of aerosol optical depth by sun photometer of SPM in the region of the Lower Volga [9292-84]

$9292 \mathrm{~W} \quad$ Model estimates of the spectral dependencies of single scattering albedo in the troposphere in different seasons [9292-125]

$92922 \mathrm{X}$ Diurnal behavior of the carbon dioxide flux and change in the isotopic ratio $\delta^{13} \mathrm{C}$ in surface and near-bottom water in littoral of Lake Baikal [9292-141]

$92922 Y \quad$ Estimate of the vertical plankton biomass profile on the basis of measurements of fluorescent characteristics in pelagial of Lake Baikal [9292-166]

$92922 Z$ Remote sensing of chemical warfare agent by $\mathrm{CO}_{2}$-lidar [9292-110]

929230 Detection of atmospheric trace gas species by DOAS gas-analyzer [9292-1 12]

$929231 \quad$ Eco-geochemical peculiarities of mercury content in solid residue of snow in the industrial enterprises impacted areas of Tomsk [9292-231]

929232 Atmospheric suspensions of Russky Island [9292-15]

929233 Density based clustering algorithm based on satellite cloud sensing [9292-209]

929234 Software platform of unified computing environment for calculations in optic atmosphere investigation [9292-64]

929235 Climatic response of annual tree-rings [9292-7]

929236 Contamination monitoring of snow cover in the vicinity of Tomsk petrochemical plant [9292-219] 
929237 Crosswind measurements from image flutter of remote objects [9292-138]

929238 Waveguide RF excited ${ }^{13} \mathrm{C}^{16} \mathrm{O}_{2}$-laser tunable from 11.04 to $11.31 \mu \mathrm{m}$ for lidar applications [9292-233]

929239 Research of optical and microphysical characteristics of near-ground aerosol in urban winter smog Tomsk in February 2014 [9292-55]

9292 3A Portable eye-safe ceilometers [9292-151]

9292 3B An overtone CO laser application for lidar measurements of profiles of atmospheric meteorological parameters [9292-1]

$92923 \mathrm{C}$ Comparison of the water vapor and aerosol profiles [9292-196]

9292 3D About scavenging of near-water submicrometer aerosol in Arctic and Sub-Arctic regions [9292-31]

9292 3E Restructuring submicron aerosol size spectrum in early spring period [9292-30]

$92923 \mathrm{~F} \quad$ Experimental study of particles and droplets generation in the binary mixture of supersaturated water vapor with air and molecular gases [9292-206]

$92923 \mathrm{G}$ Comparison of optical and microphysical properties of the atmospheric aerosol from the data of SP-6 and CE-318 solar photometers [9292-215]

$92923 \mathrm{H} \quad$ Simulation of the Raman lidar signal for localized source of atmospheric pollution [9292-48]

$929231 \quad$ Special features in the formation of double scattering in lidar signals from droplet clouds [9292-222]

9292 3J Comparative analysis of lidar investigations of aerosol in Central Asia and West Siberia [9292-116]

9292 3K Robust identification algorithms in problems of lidar sensing of the atmosphere [9292-22]

$92923 \mathrm{~L} \quad$ Software for retrieving the ozone altitude profiles from data of atmospheric laser sensing [9292-63]

$92923 \mathrm{M}$ Criterion of the need to consider the cooperative effect of the molecular absorption and aerosol scattering on calculations of IR transmission function [9292-29]

$92923 \mathrm{~N} \quad$ Estimation of the applicability of the double scattering approximation for hydrooptical laser sensing [9292-249]

929230 Comparison of remote spectrophotometric and lidar measurements of $\mathrm{O}_{3}, \mathrm{NO}_{2}$, and temperature with data of satellite measurements [9292-189]

9292 3P Experimental measurements of surface turbulent flows [9292-90]

$92923 Q \quad$ Ontologies in remote sensing data processing for urban area description [9292-102] 
$92923 R \quad$ Examining the quasibiennial oscillation of total ozone and ozone concentrations at separate stratospheric levels according to data of TOMS satellite instrumentation [9292-192]

$929235 \quad$ Relationship of spatial structure of aerosol and humidity during passage of the internal gravity wave [9292-190]

9292 3T Columnar aerosol properties retrieved from sun-sky radiometer measurements in Western Siberia during the winter season [9292-95]

$92923 \mathrm{U}$ One-parameter seasonal models of aerosol extinction for the near-ground layer of the atmosphere in arid zone [9292-75]

9292 3V Comprehensive study of optical properties of natural smoke aerosols in July 2012 in Tomsk [9292-124]

9292 3W Lidar extinction measurement in the mid infrared [9292-241]

$92923 X \quad$ Application of support vector machine method for the analysis of absorption spectra of exhaled air of patients with broncho-pulmonary diseases [9292-136]

$92923 Y \quad$ Using of laser spectroscopy and chemometrics methods for identification of patients with lung cancer, patients with COPD and healthy people from absorption spectra of exhaled air [9292-223]

$929232 \quad$ Specific features of spatial distribution of atmospheric aerosol optical depth along northern sea route [9292-53]

929240 Latitudinal distribution of the aerosol optical depth over oceans in southern hemisphere [9292-39]

$929241 \quad$ Annual behavior of the aerosol optical depth in some regions of Asian part of Russia [9292-85]

929242 Composition of atmospheric suspensions of Ussuriisk City according to snow pollution [9292-14]

929243 Altitudinal distribution of aldehydes and their contribution into organic atmospheric aerosol through photonucleation of biogenic compounds over forests in West Siberia [9292-211]

929244 Aerosol number size distributions in the lower troposphere over a background region and megalopolis (Novosibirsk) on result of airborne sounding in 2011-2013 [9292-226]

\section{ATMOSPHERIC PHYSICS}

929245 Methods of environmental quality assessments in conditions of climate variability (Invited Paper) [9292-113]

$929246 \quad$ Modeling of the river discharge from the Lena River Basin [9292-128]

929247 Simulation of atmospheric dynamics and air quality in the Baikal region [9292-93] 
929248 Modelling of urban air pollution by anthropogenic and biogenic source emissions [9292-115]

929249 Mathematical modelling of atmospheric processes above an industrial centre [9292-129]

$92924 \mathrm{~A} \quad$ Isotropic approximation errors in geometrical-optical description of ionospheric propagation of radio waves [9292-107]

9292 4B Polar glaciers and climate: about the causes of climate changes [9292-51]

9292 4C Local cloud atmosphere models as a result of climatic zoning of the Siberia territory according to the total and lower cloudiness conditions [9292-20]

9292 4D Modeling of the dynamics subsea permafrost in the East Siberian Arctic Shelf under the past and the future climate changes [9292-1 18]

$92924 \mathrm{E} \quad$ Homogeneous boundary layer model for forecasting of atmospheric processes nearby airport [9292-143]

$92924 \mathrm{~F}$ Lidar investigation of the annual variability of the background aerosol filling of the stratosphere above Tomsk in 2011-2013 [9292-203]

$92924 \mathrm{G}$ The study of the special features of winter stratospheric warming manifestations over Tomsk according to the lidar temperature measurements [9292-204]

$92924 \mathrm{H}$ Adaptation of model parameters of VLF radio signals phase variations on the NovosibirskYakutsk propagation path [9292-46]

929241 Statistics on characteristics of lightning with several return strokes in Yakutia [9292-50]

$92924 \mathrm{~J} \quad$ Variations of impulsive natural VLF signals passing over epicenters of earthquakes by observations in Yakutsk [9292-111]

9292 4K Software system for cloud classification according to MODIS satellite images [9292-4]

$92924 \mathrm{~L} \quad$ Application of the self-organizing maps for cirrus clouds recognition on satellite imagery of MODIS [9292-62]

9292 4M Some characteristics of inversions in Tomsk according to MTP-5 temperature profiler [9292-137]

$92924 \mathrm{~N}$ Analysis of spatiotemporal dynamics of the wind velocity in the atmospheric boundary layer [9292-237]

929240 Correlation features for rows averaged values of meteorological parameters obtained from measurements in regional network of the automated ultrasonic weather stations [9292-161]

$92924 \mathrm{P}$ Comparison of ASCAT satellite soil moisture measurements data with in-situ measurements [9292-134]

$92924 \mathrm{Q}$ Analysis of whistler rates in connection with lightning activity change in the world lightning centers [9292-28] 
$92924 R \quad$ Ambiguous dependence of fluorescence intensity of trees on chlorophyll concentration [9292-8]

9292 4S Wavelet analysis of wave processes in the middle atmosphere over Yakutsk during the sudden stratospheric warming of major type in January, 2010 [9292-120]

9292 4T Numerical simulation of gravity flows in the atmosphere over rough terrain [9292-83]

$92924 \mathrm{U}$ Monitoring of the Earth's ionosphere, a next-generation digital ionosonde [9292-181]

$92924 \mathrm{~V}$ Resonances in the Earth-ionosphere cavity according to the data of magnetic observations in Tomsk [9292-188]

$92924 \mathrm{~W} \quad$ Long-term trends of the critical frequency of the F2-layer of the ionosphere [9292-183]

$92924 X \quad$ Spatial distribution of the electric field intensity in the city of Tomsk [9292-178]

$92924 \mathrm{Y}$ The results of monitoring studies of the acoustic fields in Tomsk [9292-175]

$92924 Z$ Estimation of ground explosions energy by using infrasound monitoring data [9292-121]

929250 Ultra-wideband tomography of land cover [9292-216]

929251 Influence of infrasonic fields on electrical activity of a human brain [9292-187]

929252 GPS-derived zenith tropospheric delay assimilation into numeric atmosphere model [9292-228]

929253 Study of wind shear over forested areas around airport runway [9292-24]

929254 Complex experiment on the study of microphysical, chemical, and optical properties of aerosol particles and estimation of atmospheric aerosol contribution in the Earth radiation budget [9292-193]

929255 Variations of parameters ELF-VLF noise and VLF signals on the DEMETER satellite over the seismic activity region [9292-18]

929256 Estimation of changes in the variability of human heart rate under the impact of weak acoustic fields [9292-177]

929257 Simulation of aerosol substance transfer in the atmospheric boundary layer [9292-131]

929258 Optic detectors calibration for measuring ultra-high energy extensive air showers Cherenkov radiation by $532 \mathrm{~nm}$ laser [9292-79]

929259 Active experiments in the ionosphere and geomagnetic field variations [9292-34]

9292 5A Study of thunderstorm activity connection with weather system structures over the NorthWestern Pacific Ocean [9292-33]

9292 5B Atmospheric circulation influence during winter on change of air pressure, temperature and spectral transparency at Yakutsk Array [9292-80] 
9292 5C Experimental studies of ozone and temperature variations in the stratosphere over Tomsk by the methods of microwave and lidar sensing [9292-201]

9292 5D Distribution of extreme temperatures in the Altai Mountains [9292-246]

$92925 \mathrm{E} \quad$ lonosphere effects of tropical cyclones over the Asian region of Russia according to oblique radio-sounding data [9292-16]

$92925 \mathrm{~F}$ Turbulence anisotropy in the near-ground atmospheric layer [9292-106]

$92925 \mathrm{G}$ Structure tensor of wind velocity components in the near-ground atmospheric layer [9292-119]

$92925 \mathrm{H}$ Influence the solar activity and quasi-biennial oscillations on surface air temperature variations in Yakutia [9292-41]

929251 Height distribution of the upper atmosphere continuum infrared emissions [9292-40]

9292 5J Ozone vertical flux within the lower troposphere over background areas of West Siberia [9292-36]

$92925 \mathrm{~K} \quad$ Lidar investigations of the special features of vertical distributions of the temperature and atmospheric density during the periods of quiet and perturbed states of the stratosphere [9292-205]

$92925 \mathrm{~L} \quad$ Evaluation of the capability of lidar placed onboard an orbital platform to measure the atmospheric density profiles [9292-202]

$92925 \mathrm{M}$ Potential for lidar measurements of temperature from space [9292-230]

$92925 \mathrm{~N} \quad$ Radio signal correlation at frequency $32 \mathrm{MHz}$ with extensive air showers parameters using Yakutsk array data [9292-91] 
Proc. of SPIE Vol. $9292929201-14$

Downloaded From: https://www.spiedigitallibrary.org/conference-proceedings-of-spie on 26 Apr 2023 Terms of Use: https://www.spiedigitallibrary.org/terms-of-use 


\section{Authors}

Numbers in the index correspond to the last two digits of the six-digit citation identifier (CID) article numbering system used in Proceedings of SPIE. The first four digits reflect the volume number. Base 36 numbering is employed for the last two digits and indicates the order of articles within the volume. Numbers start with 00, 01, 02, 03, 04, 05, 06, 07, 08, 09, OA, OB...0Z, followed by 10-1Z, 20-2Z, etc.

\author{
Abramochkin, Vladimir N., 10 \\ Afanasiev, Alexey L., 37, 3P \\ Afonin, S. V., 54 \\ Ageev, Boris G., 35 \\ Akhlestin, A. YU., OA \\ Akhmetshina, A. S., 4M \\ Akopdjanan, Yuri A., OX \\ Aksenov, Valery A., 1M, $2 \mathrm{G}$ \\ Aksenov, V.P., OQ \\ Anshits, A. G., 2K \\ Antokhin, P. N., 54, 5J \\ Antokhina, O. YU., 5J \\ Antopov, Oleg, $1 \mathrm{~J}$ \\ Antoshkin, L. V., 13 \\ Anufriev, I. S., 26 \\ Apeksimov, D. V., 1B, 1C, 1D \\ Argunov, Vyacheslav V., 4J \\ Arsenyan, Tatiana I., 16 \\ Arshinov, M. YU., 3C, 54 \\ Arshinova, V. G., 54 \\ Artyushina, A. V., OL \\ Astafurov, V. G., 4K, 4L \\ Auyrov, D. B., 55 \\ Axyonov, S. V., 4L \\ Azbukin, A. A., 2A \\ Babanin, Eugeniy A., 16 \\ Babchenko, S. V., 2J \\ Babichenko, S., 3W \\ Baklykova, E. S., 56 \\ Balin, Yurii S., 28, 3C, 3J, 54 \\ Banakh, Viktor A., 18, 1L, 1N, 1Q, 1S, 1U, 37 \\ Bart, Andrey A., 48, 49 \\ Bashkuev, Y. B., 55 \\ Bazarov, Kim B., OS \\ Bazhenov, O. E., 3O, 3R \\ Bedareva, Tatiana V., OL, 3T, 54 \\ Belan, Boris D., 3C, 44, 54, 5J \\ Belan, D. B., 54 \\ Belan, S. B., 54, 5J \\ Belov, Vladimir V., 10, 2B, 54 \\ Beresnev, Sergey A., OZ, 41 \\ Beshta, O. A., 2V \\ Bilanchuk, Vyacheslav $\vee ., 0 X$ \\ Bobrov, E. V., 05, 2V \\ Bobrovnikov, Sergey M., 2G, 3H \\ Bocharov, A. A., 4X, 4Y \\ Bochkovskii, D. A., 2F, 2I, 5C, 5K, 5M \\ Bogdanova, Julia $\vee ., 0 G$ \\ Bogoslovskiy, Nikolay N., 49, 4P
}

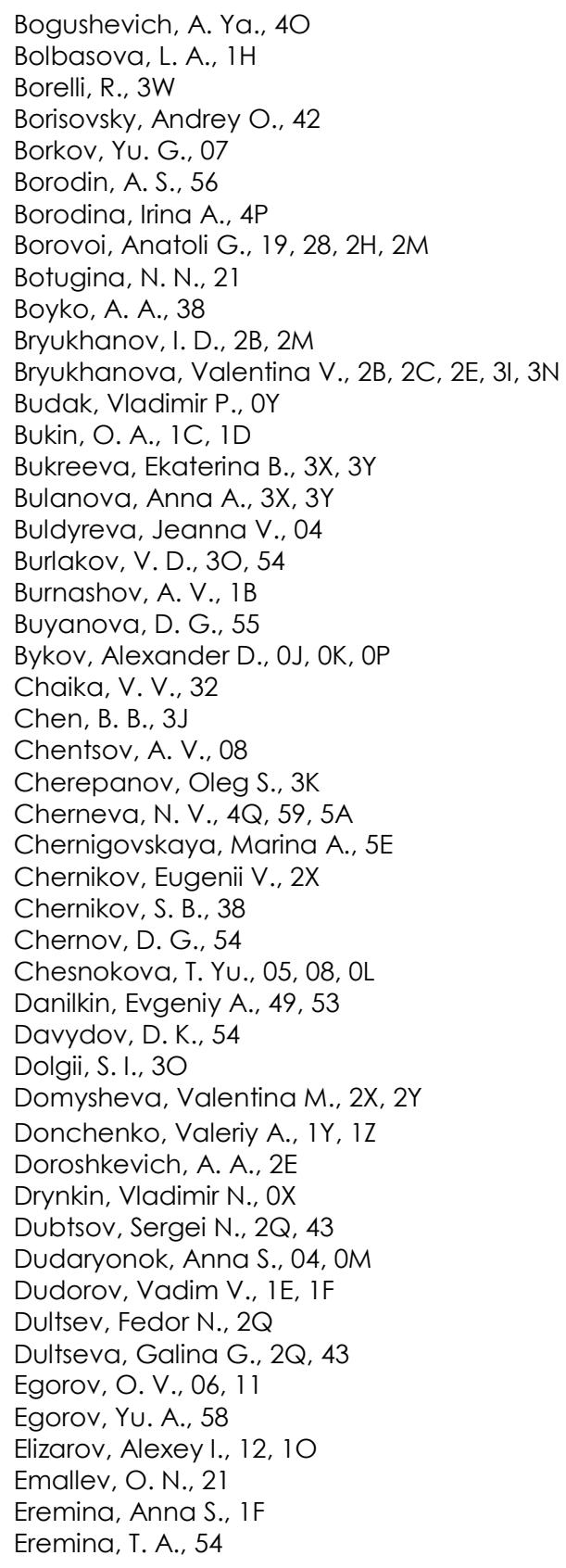


Erin, Sergey I., 4P

Evsyutkin, T. V., 4L

Faleychik, Larisa M., 47

Falits, A. V., 1N, 1Q

Falkov, Eduard Y., OX

Fazliev, Alexander Z., 09, OA, OB, OC

Fedorov, V. A., 5F, 5G

Filimonenko, Ekaterina A., 31, 36

Fiorani, L., 3W

Firsov, K. M., 05, 09, 2V

Fofonov, A. V., 54

Fomenko, Anatoly I., OX

Galileiskii, Viktor P., 12

Geiko, Pavel P., 2Z, 30

Geints, Yurii E., 1A, 11, 1X

Gladkikh, V. A., 21, 54, 5F, 5G

Goleneva, N. V., 13, 1P

Golik, S. S., 1C, 1D

Golokhvast, Kirill S., 32, 42

Golubeva, Elena N., 4D

Gorbatenko, V. P., 4M

Gorda, Stanislav YU., 41

Gorlov, Evgeny V., 2G, 3H

Goryachev, B. V., OD, OE

Grachev, G. N., 1X

Gricuta, A. N., 3A

Gridnev, Yu. V., 30

Grigoriev, Victor M., OV

Grigorov, I., 3W

Grishaev, M. V., 30, 54

Grishin, A. I., 3A

Gruzdev, Aleksandr N., 35

Gryazin, V. I., OZ

Gulev, Sergey K., 40

Holben, Brent N., 40, 41

Holzworth, Robert, 5A

Horoshaeva, E. E., 1C, 1D

Hu, Shunxing, 28

Iglakova, A. N., 1B, 1C

Il'in, S. N., 4C

Ionin, A. A., 07

Ivlev, G. A., 54

Jouravlev, A. A., 52

Kabanov, A. M., 1B, 1C, 1D, 1X

Kabanov, Dmitry M., 2V, 3G, 3Z, 40, 41, 54

Kabanov, Mikhail M., 3Q

Kalayda, Vladimir T., 33, 34

Kalchikhin, V. V., 2A

Kalinin, K. V., OJ

Kamardin, A. P., 54

Kanev, Feodor, 1 J, 1M

Kapegesheva, O. F., 2O, 4N

Kapitanov, Venedikt A., 02, 03

Kapustin, Sergey N., $3 Q$

Karapuzikov, A. A., 38

Karapuzikov, A. I., 38

Karimov, Rustam R., 4H

Kashirskii, D. E., 11, 3M

Kaul, B. V., 2B

Khaitov, Rustam K., 4U, 4W
Kharchenko, O. V., 2F, 3B

Khomutov, S. Y., 59

Khristoforova, Nadezhda K., 42

Khutorov, V. E., 52

Khutorova, O. G., 52

Kikhtenko, Andrey V., $2 \mathrm{G}$

Kinyaevskiy, I. O., 07

Kirillov, Nikolay S., 2D

Kistenev, Yury V., 3X, 3Y

Kizhner, Lubov I., 4M, 4P

Klimachev, Yu. M., 07

Klimeshina, Tatyana E., OF, OG, OH, OP

Klimkin, A. V., 3F

Klitochenko, I. I., 05, 2V

Klokov, Andrey $\vee ., 50$

Knurenko, S. P., 58, 5B, 5N

Kobzev, A. A., 2A

Kochetkova, Tatiana D., 50

Kochneva, L. B., OZ

Kokarev, Dmitrii $\vee ., 12$

Kokhanenko, Grigorii P., 28, 3C, 3J, 3S, 54

Kolesnik, E. S., 4U

Kolesnik, Sergei A., 4U, 4V, 4W

Kolmakov, A. A., 4V

Kolosov, Valery $\mathrm{V} ., 0 \mathrm{Q}, 1 \mathrm{E}$

Komarov, Aleksandr G., 16

Komarov, V.S., 4C

Konoshonkin, Alexander V., 19, 28, 2H, 2M

Konyaev, Peter A., 1T, 21

Kopyev, E. P., 26

Kornienko, Gennady I., 41

Korolkov, V. A., 2A, 40

Korsakov, Alexey A., 4H

Kotkov, A. A., 07

Kovadlo, Pavel G., OT, OV, 1V, 4B

Kozlov, A. S., 3F, 54

Kozlov, A. Yu., 07

Kozlov, Artem V., 44, 54, 5J

Kozlov, Valeriy S., 2W, 39, 3V, 54

Kozlov, Vladimir I., 4H, 4I

Kozodoev, A. V., OA

Krasnenko, N. P., 2O, 4N

Krasnov, O. A., 5J

Krasnov, V.I., 52

Krivtsov, I. A., 33

Kruglova, T. V., OK

Kryuchkov, A. V., 3A

Kuchinskaya, O. I., 1B, 1C, 1D

Kuksenok, Dmitry, 1M

Kulikov, Yu. Yu., 5C

Kulipanov, G. N., 2J

Kurbatskaya, L., OR

Kurbatskiy, A., OR

Kurjak, A. N., 3F

Kurkin, Vladimir I., 4A, 5E

Kustova, Natalia V., 19, 28, 2H, 2M

Kuzin, Viktor I., 46

Kuzmin, Dmitry A., 3X, 3Y

Kuznetcova, I. B., 38

Laikom, D. N., 4K 
Lapteva, Natalya A., 46

Laryunin, O. A., 4A

Lavrentiev, N. A., 09, 0A

Lavrentieva, Nina N., 04, 0M, 00

Lavrinenko, A. V., 4C

Lavrinov, V. V., 13, 1P

Lavrinova, L. N., 13, 1P

Lezhenin, A. A., 57

Lisenko, A. A., 2J, 2K

Liu, Dong, 28

Loboda, E. L., 14, 15, 22, 23, 24, 25, 26

Lomakina, N. Ya., 4C

Lubenko, D. M., 2K

Lugovskoi, A., ON, 00

Lukin, Igor P., 1G, 1K, 1R, 20

Lukin, Vladimir P., OU, OV, OW, 1H, 1T, 21

Lyapina, E. E., 31

Ma, Qiancheng, OM

Machikhin, Alexander S., OX

Makarov, Vladislav, 27

Makeev, A. P., 30, 3R

Makenova, Nailia A., $1 \mathrm{~J}$

Maksimova, Tatyana A., 43, 54

Malakhova, Valentina $V ., 4 D$

Malyshkin, S. B., 3F, 54

Marakasov, Dmitri A., 17

Marichev, V. N., 2I, 4F, 4G, 5C, 5K, 5L, 5M

Maskaeva, Anastasiya A., 43

Matrosov, I. I., 29

Matthey, Renaud, 27

Matvienko, G. G., 1B, 1C, 1D, 2F, 2J, 2K, 2N, 54,

$5 \mathrm{~L}$

Mayor, A. V., ID

Medvedeva, I. V., 5 I

Melnikov, Nikolai G., 17

Menshchikova, S. S., 3G

Mik, Ivan A., 2Q

Miroshnichenko, I. B., 38

Miroshnichenko, M. B., 38

Mitaev, A. A., 4U

Mitev, Valentin, 27, 3W

Mogilnitskiy, S. B., OD, OE

Morozov, Aleksandr M., 12

Mullayarov, Viktor A., 4H, 4l, 4J

Nadeina, Luisa $\vee ., 36$

Nakhtigalova, D. P., 4C

Nasonov, Sergey V., 1O, 2B, 2L, 2M

Nasrtdinov, Ilmir M., OL, 3T

Naumenko, O. V., OA, OB

Nebosko, Evgeny Yu., $2 \mathrm{U}$

Nedosekov, D. A., 4V

Nee, E. V., 3l

Nevzorov, Aleksey A., 3L

Nevzorov, Aleksey V., 3L, 30

Nevzorova, I. V., 5F, 5G

Nikiforov, P. A., 32

Nikiforova, Olga Yu., 3Y

Nikolashkin, Semen V., 41, 4S, 5H

Nosov, Evgeny V., OU, OV

Nosov, P. A., 2P
Nosov, Victor V., OU, OV

Nuternan, Roman B., 53

Nuvoli, M., 3W

Odintsov, S. L., 21, 54, 5F, 5G

Oinats, Alexey V., 5E

Oppel, Ulrich G., OS

Oshlakov, V. K., 1B, 1C, 1D, 2J, 2K

Osipov, Konstantin Yu., 02, 03

Padalko, Natalia L., 2X

Palucci, A., 3W

Panamarev, Nikolay S., 1Y, $1 Z$

Panamaryova, Anna N., 1Y, $1 Z$

Panchenko, Mikhail V., 2T, 2W, 2X, 2Y, 39, 3E, 3V, 54

Panchenko, Yury N., 2G

Panina, Ekaterina K., 1A, 11

Parygina, I. A., 31

Pavlov, A. A., $1 \mathrm{X}$

Pavlov, A. A., $1 \mathrm{X}$

Penenko, Vladimir V., 45, 47

Penner, logannes E., 28, 3C, 3J, 54

Perminov, V. A., 24, 25

Permyakov, M. S., 5A

Pestunov, Dmitrii A., 2X, 2Y, 54, 5J

Petrov, A. K., 3F

Petrov, Alexey A., 34

Petrov, A. V., 1B, 1C, 1D, 1X

Petrov, D. V., 29

Petrov, I. S., 58, 5B, 5N

Pikalov, M. V., $4 \mathrm{U}$

Pinaev, P. A., $1 X$

Pistilli, M., 3W

Pkhalagov, Yuri A., 2S, 2T, 3U, 3V

Pobachenko, S. V., 4X, 51, 56

Poddelsky, Igor N., 5E

Pogodaev, V. A., $1 \mathrm{X}$

Pogutsa, Cheslav E., 0Q, 1M

Pol'kin, Vasiliy V., 2T, 39, 3D, 3E, 3V, $3 Z$

Pol'kin, Victor V., 2T, 2W, 39, 3D, 3E, 3V, 54

Polovtseva, E. R., OB, OJ, OK

Ponomarenko, A. G., $1 X$

Ponomarev, Yurii N., 08, 35, 38, 3F, 3Y

Ponurovskiy, Yakov Ya., 02, 03

Popovskaya, Galina I., $2 Y$

Potalova, E. Yu., 5A

Prakhov, Aleksander N., $3 Z$

Prazdnichnykh, Maxim I., 2X

Prigarin, Sergei M., OS

Prikhodko, L. I. IW

Privezentsev, Alexei I., 09, 0A, 0C

Protasevich, Alexander E., 02, 03

Provotorov, D. S., $4 Z$

Puiu, Ad., 3W

Pyanova, Elza A., 47

Radionov, Vladimir F., 40

Rahm, S., $1 U$

Raputa, V. F., 57

Rasskazchikova, T. M., 54

Razenkov, I. A., is

Rebane, Ott, 3W 
Reyno, V. V., 14, 15, 22, 23, 24, 25

Rodimova, Olga B., OF, OG, OH, OP

Romanovskii, Oleg A., 2F, 3B, 3L, 54

Rostov, Andrey P., 37, 3P, 54

Ryskin, V. G., 5C

Rytchkov, D. S., 18

Ryumkin, Alexander I., $3 Q$

Safatov, A. S., 54

Sakerin, Sergey M., 3G, 3Z, 40, 41, 54

Sakirko, Maria V., $2 Y$

Salnikova, N. S., 30

Samoilova, S. V., 3J, 54

Samokhvalov, Ignatii $V$. ., 1Y, 1Z, 2B, 2D, 2E, 2L, 2M,

$30,4 \mathrm{~F}, 4 \mathrm{G}, 5 \mathrm{~K}$

Santoro, S., 3W

Sapozhnikova, Valeria A., 35

Sarychev, Valeri T., 4W

Savkin, D. E., 54

Sazanovich, Valentina M., 17

Scherbakov, A. P., OK

Semenov, A. I., 5I

Sennikov, Victor A., IT

Serduykov, V. I., OJ, OK

Serovetnikov, A. S., 59

Shagalov, Oleg $V .$, OY

Shamanaev, Vitalii S., 3N, 5L

Shamanaeva, L. G., 2O, 4N

Sharapova, A. A., 5D

Shchelkanov, N. N., 3U

Shcherbakov, A. P., OJ

Shefer, Nadezhda A., 3P, 54

Shefer, O. V., 3M

Shefov, N. N., 5 I

Shelekhov, A. P., 4M

Shelekhova, E. A., 4M

Sherbakov, A., 00

Shesternin, Andrei N., 17

Shevtsov, B. M., 4Q, 5A

Shikhovtsev, A. YU., OT, IV

Shimaraev, Mikhail N., $2 Y$

Shipilov, Sergey E., 50

Shirokov, I. A., IW

Shlychkov, V. A., 57

Shmargunov, Vladimir P., 2T, 3V, 54

Shmirko, Konstantin A., $3 Z$

Shtyrov, M. YU., 38

Simakhin, Valery A., 3K

Simonenkov, Denis $\vee$., 44, 54

Sinitsa, L. N., OJ, OK, ON, 00

Sitnikov, Grigory I., 4E

Sivokon, V. P., 59

Sklyadneva, T. K., 54

Skorokhodov, A. V., 4K

Smalikho, I. N., IU

Smirnov, A. L., $1 X$

Smirnov, Alexander, 40, 41

Smirnov, Sergey S., 2Z, 30

Soboleva, Elena V., 42

Sokolov, K. I., 5D

Sokolova, E. B., 1C, 1D
Solodov, A. A., 08

Solodov, A. M., 08

Soloviev, A. V., 4X

Solovyev, Vladimir S., $2 R$

Solovyov, A. V., 4Y, 4Z, 51, 56

Sorokin, I. V., 5L

Spitcin, V. V., 38

Starchenko, Alexander V., 48, 49, 4E, 53

Starikova, M. K., 38

Statsenko, P. A., $1 X$

Stykon, A. P., 2E, 2M

Suhareva, Natalia A., 16

Sukhanov, A. Ya., 2K, $2 \mathrm{~N}$

Sukharev, A. A., $1 \mathrm{~N}$

Sulakshina, O. N., 07

Sverdlik, L. G., 3J

Svetlichny, $0 ., 00$

Sviridenkov, Mikhail A., 2U, 3T

Talipov, D. V., 56

Talovskaya, Anna V., 31, 36

Tarabukina, L. D., 4I

Tarasenkov, Mikhail V., 10, 2B

Taschilin, Mikhail A., 41

Terenteva, Mariya $\vee$., 49, 4E, 53

Terpugova, Svetlana A., 2W, 39, 3E, 3S, 3V, 54

Tikhomirov, A. A., 29, 2A, 4O, 5L

Tikhomirova, O. V., OQ, 54

Tikhonyuk, I. I., 38

Tischenko, V. N., $1 \mathrm{X}$

Titov, S. T., 4S

Tivileva, Maria I., 2G

Tolmachev, Gennadii N., 44, 54

Tomshin, Oleg A., 2R

Torgaev, Andrey V., OU, OV, 21

Tsareva, Tatiana I., OX

Tsarkov, Dmitry $\vee ., 0 C$

Tsaruk, Victoria $V ., 44$

Tsvetova, Elena A., 45

Tsvyk, Ruvim Sh., 17

Tsyro, Ekaterina, $1 \mathrm{~J}$

Tumakov, Alexander G., 2T, 2X, 3V

Turchinovich, S. A., 54

Turchinovich, YU. S., 54

Tuzhilkin, D. A., 56

Tuzikov, Sergei A., 3X, 3Y

Usoltseva, Marina V., $2 Y$

Uzhegov, Viktor N., 2S, 2T, 3V

Vasil'chenko, S. S., OJ, OK

Vasiliev, M. S., 5H

Vasiljeva, M. S., $\mathrm{OZ}$

Veretennikov, V. V., $3 G$

Vlasenko, Sergey S., $2 U$

Vodinchar, G. M., 4Q

Voitsekhovskaya, O. K., 06, 11, 3M

Voitsekhovskii, A. V., 11

Volkov, S. N., 2M

Vologdin, A. G., IW

Voronin, B. A., Ol, 1H, 3C

Voronina, Svetlana S., OA, OB, OC

Voronina, Yu., 09

xviii

Proc. of SPIE Vol. $9292929201-18$ 
Voznesenskaya, K. V., 4X

Vypirailo, D. N., 51

Wang, Yingjian, 28

Wang, Zhenzhu, 28

Wu, Decheng, 28

Xie, Chenbo, 28

Yakovlev, S. V., 2F, 3B

Yakubov, Vladimir P., 50

Yausheva, Elena P., 39, 3V, 54

Yazev, S. A., 4B

Yazikov, Egor G., 36

Yudin, M. S., 4T

Yumov, Evgeny L., 3X, 3Y

Yurchenko, Alexey $\vee$., 50

Zaloznaya, I. V., $1 \mathrm{~L}$

Zapasnoy, Andrey S., 50

Zavoruev, Valeriy V., 2Y, 4R

Zavorueva, Elena N., $4 R$

Zemlyanov, Alexander A., 1A, 1B, 1C, 1D, 1I, 1X

Zharkov, Viktor I., 2G, 3H

Zheltov, Victor S., OY

Zhuravleva, Tatiana B., OL, 3T

Zotov, Aleksey M., 16

Zuev, V. V., 4M

Zuravleva, T. B., 54

Proc. of SPIE Vol. $9292929201-19$ 
Proc. of SPIE Vol. $9292929201-20$

Downloaded From: https://www.spiedigitallibrary.org/conference-proceedings-of-spie on 26 Apr 2023 Terms of Use: https://www.spiedigitallibrary.org/terms-of-use 


\section{Conference Committees}

Conference Chairs

Gelii A. Zherebtsov, Institute of Solar-Terrestrial Physics

(Russian Federation)

Gennadii G. Matvienko, V.E. Zuev Institute of Atmospheric Optics

(Russian Federation)

Organizer Committee

Oleg A. Romanovskii, Co-chair, V.E. Zuev Institute of Atmospheric Optics (Russian Federation)

Alexander S. Kozlov, Co-chair, Institute of Chemical Kinetics and Combustion (Russian Federation)

Semen V. Yakovlev, Scientific Secretary, V.E. Zuev Institute of Atmospheric Optics (Russian Federation)

International Advisory Committee

L. C. Andrews, University of Central Florida (United St ates)

R. L. Armstrong, New Mexico State University (United States)

S. N. Bagaev Institute of Laser Physics, Oceanology (Russian Federation)

O. A. Bukin, Marina State University, Oceanology (Russian Federation)

C. Camy-Peyret, CNRS, Université Pierre-et-Marie-Curie (France)

A. Comeron, Polytechnic University of Catalunya (Spain)

A. Consortini, Università degli Studi di Firenze (Italy)

G. S. Golitsyn, Institute of Atmospheric Physics Oceanology (Russian Federation)

A. P. Ivanov, Institute of Physics (Belarus)

O. V. Kopelevich, Institute of Oceanology (Russian Federation)

U. N. Singh, NASA Langley Research Center (United States)

A. P. Potekhin, Institute of Solar-Terrestrial Physics (Russian Federation)

Gengchen Wang, Institute of Atmospheric Physics (China)

Program Committee

E. I. Akopov, SPIE Russian Chapter (Russian Federation)

L. C. Andrews, University of Central Florida (United States)

A. Ansmann, Leibniz-Institute for Tropospheric Research (Germany)

K. Asai, Tohoku Institute of Technology (Japan)

V. A. Banakh, Institute of Atmospheric Optics (Russian Federation) 
A. Barbe, Université de Reims Champagne-Ardenne (France)

B. D. Belan, Institute of Atmospheric (Russian Federation)

V. V. Belov, Institute of Atmospheric Optics (Russian Federation)

L. R. Bissonnette, Defence Research and Development Canada (Canada)

P. Bruscaglioni, Università degli Studi di Firenze (Italy)

Bruce Dean, NASA Goddard Space Flight Center (United States)

G. S. Golitsyn, Institute of Atmospheric Physics (Russian Federation)

G. I. Gorchakov, Institute of Atmospheric Physics (Russian Federation)

G. Inoue, National Institute for Environmental Studies (Japan)

A. P. Ivanov, B.J. Stepanov Institute of Physics (Belarus)

V. P. Kandidov, Moscow State University (Russian Federation)

B. A. Kargin, Institute of Computational Mathematics and Mathematical Geophysics (Russian Federation)

A. Kohnle, FGAN-FOM (Germany)

P. G. Kovadlo, Institute of Solar-Terrestrial Physics (Russian Federation)

V. A. Kovalenko, Institute of Solar-Terrestrial Physics

(Russian Federation)

V. E. Kunitsyn, Moscow State University (Russian Federation)

V. I. Kurkin, Institute of Solar-Terrestrial Physics (Russian Federation)

V. P. Lukin, Institute of Atmospheric Optics (Russian Federation)

G. G. Matvienko, Institute of Atmospheric Optics (Russian Federation)

U. G. Oppel, Ludwig-Maximilian-Universität Munich (Germany)

M. V. Panchenko, Institute of Atmospheric Optics (Russian Federation)

V. V. Penenko, Institute of Computational Mathematics and Mathematical Geophysics (Russian Federation)

Y. N. Ponomarev, Institute of Atmospheric Optics (Russian Federation)

A. P. Potekhin, Institute of Solar-Terrestrial Physics (Russian Federation)

S. Rahm, DLR Institute of Atmospheric Physics (Germany)

J. C. Ricklin, Defense Advanced Research Projects Agency

(United States)

M. C. Roggemann, Michigan Technological University (United States)

I. V. Samokhvalov, Tomsk State University (Russian Federation)

U. N. Singh, NASA Langley Research Center (United States)

L. N. Sinitsa, Institute of Atmospheric Optics (Russian Federation)

O. K. Steinvall, Swedish Defence Research Agency (Sweden)

G. F. Tulinov, Institute of Applied Geophysics (Russian Federation)

M. A. Vorontsov, University of Maryland (United States)

Gengchen Wang, Institute of Atmospheric Physics (China)

A. A. Zemlyanov, Institute of Atmospheric Optics (Russian Federation) 
Session Chairs

1 Conference A: Molecular Spectroscopy and Atmospheric Radiative Processes

L. N. Sinitsa, Institute of Atmospheric Optics (Russian Federation)

C. Domingo, Instituto de Estructura de la Materia, CSIC (Spain)

L. A. Surin, Universität zu Köln (Germany)

Yu. N. Ponomarev, Institute of Atmospheric Optics

(Russian Federation)

2 Conference B: Optical Radiation Propagation in the Atmosphere and Ocean

V. P. Belov, Institute of Atmospheric Optics (Russian Federation)

V. P. Kandidov, Moscow State University (Russian Federation)

V. V. Kolosov, Institute of Atmospheric Optics (Russian Federation)

M. A. Vorontsov, University of Maryland (United States)

3 Conference C: Optical Investigation of Atmosphere and Ocean

V. V. Penenko, Institute of Computational Mathematics and Mathematical Geophysics (Russian Federation)

A. P. Chaikovsky, Institute of Physics (Belarus)

S. M. Sakerin, Institute of Atmospheric Optics (Russian Federation)

G. G. Matvienko Institute of Atmospheric Optics (Russian Federation)

4 Conference D: Atmospheric Physics

B. D. Belan, Institute of Atmospheric Optics (Russian Federation)

A. P. Potekhin, Institute of Solar-Terrestrial Physics (Russian Federation)

V. A. Kovalenko, Institute of Solar-Terrestrial Physics (Russian Federation)

V. N. Marichev, Institute of Atmospheric Optics (Russian Federation) 
Proc. of SPIE Vol. $9292929201-24$

Downloaded From: https://www.spiedigitallibrary.org/conference-proceedings-of-spie on 26 Apr 2023 Terms of Use: https://www.spiedigitallibrary.org/terms-of-use 


\section{Introduction}

In accordance with the meeting schedule approved by the Presidium of the Siberian Branch of the Russian Academy of Sciences for 2014, the V.E. Zuev Institute of Atmospheric Optics, V.V. Voevodsky Institute of Chemical Kinetics and Combustion, and Institute of Solar-Terrestrial Physics organized the Twentieth International Symposium titled Atmospheric and Ocean Optics/Atmospheric Physics in Novosibirsk, Russia, 23-27 June 2014.

We wish to thank our sponsors for their contribution to the success of the symposium: Siberian Branch of the Russian Academy of Sciences, and the Russian Foundation for Basic Research.

English and Russian were the working languages of the symposium. All poster presentations were in English and oral presentations were made in English and Russian (using synchronous translation via personal audio-equipment).

We conducted four conferences titled:

A. Molecular Spectroscopy and Atmospheric Radiative Processes

B. Optical Radiation Propagation in the Atmosphere and Ocean

C. Optical Investigation of Atmosphere and Ocean

D. Atmospheric Physics

The main topics of the Twentieth International Symposium on Atmospheric and Ocean Optics/Atmospheric Physics included:

- Molecular spectroscopy of atmospheric gases

- $\quad$ Absorption of radiation in atmosphere and ocean

- $\quad$ Radiative regime and climate problems

- $\quad$ Models and data bases for atmospheric optics and physics

- Wave propagation in random inhomogeneous media

- $\quad$ Adaptive optics

- $\quad$ Nonlinear effects at radiation propagation in atmosphere

- Multiple scattering in optical remote sensing

- $\quad$ Image transfer and processing

- Optical and microphysical properties of atmospheric aerosol and suspension in water media

- Transport and transformation of aerosol and gas components in the atmosphere

- Laser and acoustic sounding of atmosphere and ocean

- Diagnostics of state and functioning of plants bio systems

- $\quad$ Structure and dynamics of the lower and middle atmosphere

- Dynamics of the atmosphere and climate of the Asian region

- $\quad$ Physical processes and phenomena in the atmosphere

- $\quad$ Optic techniques for probing the atmosphere. 
History: A symposium on Atmospheric and Ocean Optics has been held annually 1994 by the Institute of Atmospheric Optics. From 1971 to 2014 the IAO organized more than 60 conferences on different scientific topics. The current symposium is the only one in Russia where fundamental problems of propagation in inhomogeneous media and the scattering and absorption radiation are considered. Very few conferences in the world have such a spectrum of interest. It is very appealing for participants (from 16 countries) that the official languages of are both Russian and English.

In the fields listed here, the Siberian scientific schools are leaders in our country and well known in the world. This fact can be attributed to the interest in symposium from the scientists of Russia and several other countries.

Present: The Twentieth International Symposium Atmospheric and Ocean Optics/Atmospheric Physics was successfully held in Novosibirsk, Russia, 23-27 June 2014.

The program included 10 invited and plenary papers, 181 oral presentations, and more than 150 poster presentations during four poster sessions.

\section{Gennadii G. Matvienko Oleg A. Romanovskii}

